archives

of thermodynamics

Vol. 38(2017), No. 4, 109-125

DOI: $10.1515 /$ aoter-2017-0027

\title{
Online monitoring system of air distribution in pulverized coal-fired boiler based on numerical modeling
}

\author{
PIOTR ŻYMEŁKA* \\ DANIEL NABAGEO \\ TOMASZ JANDA \\ PAWEE MADEJSKI
}

Research and Development Department, EDF Polska S.A. Ciepłownicza 1, 31-357 Kraków, Poland

\begin{abstract}
Balanced distribution of air in coal-fired boiler is one of the most important factors in the combustion process and is strongly connected to the overall system efficiency. Reliable and continuous information about combustion airflow and fuel rate is essential for achieving optimal stoichiometric ratio as well as efficient and safe operation of a boiler. Imbalances in air distribution result in reduced boiler efficiency, increased gas pollutant emission and operating problems, such as corrosion, slagging or fouling. Monitoring of air flow trends in boiler is an effective method for further analysis and can help to appoint important dependences and start optimization actions. Accurate real-time monitoring of the air distribution in boiler can bring economical, environmental and operational benefits. The paper presents a novel concept for online monitoring system of air distribution in coal-fired boiler based on real-time numerical calculations. The proposed mathematical model allows for identification of mass flow rates of secondary air to individual burners and to overfire air (OFA) nozzles. Numerical models of air and flue gas system were developed using software for power plant simulation. The correctness of the developed model was verified and validated with the reference measurement values. The presented numerical model for real-time monitoring of air distribution is capable of giving continuous determination of the complete air flows based on available digital communication system (DCS) data.
\end{abstract}

${ }^{*}$ Corresponding Author. Email: piotr.zymelka@edf.pl 
Keywords: Pulverized coal-fired boiler; Air distribution; Online monitoring system; Coal combustion; Combustion airflow neasurement; Numerical modeling

\section{Introduction}

Nowadays, the worldwide energy sector is under transformation as a consequence of the increasing deployment of renewable energy sources (RES), mostly wind and solar, combined with smart grids in the electricity generation system. For this reason, the conventional thermal power plants are required to stabilize and balance power grids by compensating for the variable electricity supply from RES. The current structure of power generation requires from fossil-fuel plants the ability to adapt to dynamic conditions and high flexibility to provide support for grid reliability. However, to meet these requirements it is necessary to keep the performance of thermal systems at the highest possible level due to economic and ecological aspects. The demand of lowering pollutant emissions and increasing power plant efficiency leads to upgrading the quality of combustion process and steam production in large-scale pulverized coal (PC) boilers. Performance optimization at different load conditions allows us to evaluate the capabilities and limitations of the combustion process [1-3].

One of the main objectives in the operation of modern combustion systems is to provide the low-pollution process with primary and secondary measures. Achieving the required emission levels can be obtained by the proper selection of combustion process parameters (e.g., the amount of excess air) and modification in firing system, such as burner redesign or air staging. The efficiency of combustion process strictly relates to the optimum balance of air to fuel. The optimal air-to-fuel ratio is one of the most important parameter affecting the boiler efficiency [4-7]. Information about the flow rate of combustion air is a fundamental parameter in control of boiler performance. Unreliable information about the airflow distribution in coal-fired boilers can result in the abnormal combustion process, overheating in the back-pass as well as slagging and fouling. However, measuring the combustion airflow can be difficult because of high flow rates at low pressures through irregular and large ducts. The online monitoring system of secondary air distribution in pulverized coal-fired boilers can provide additional information needed to reach optimal process efficiency and reduce pollutant emissions [8-14].

Study presented in this paper was performed in order to analyze the air 
distribution in the front-fired pulverized coal boiler of 225 MWe power unit, operating in extended load range (from 90-225 MWe). Currently, the mass flow rate of secondary air flow supplying the OFA nozzles and burners is not measured in the unit control system. The proposed numerical model allows the identification of mass flow rates of secondary air to individual burners and to OFA nozzles. Numerical models of air and flue gas system were developed with the commercial program for power plant simulation EBSILON§Professional. Obtained results provide detailed information on the secondary air flow propagation in the wind-box, hot and cold ducts. The simulation results were compared and validated with the reference measurement values. The presented numerical model for real-time monitoring of air distribution can provide information about the current air mass flow rates (primary air (PA), secondary air (SA) and overfire air (OFA)) based on available digital communication system (DCS) data.

\section{Characteristic of air and fuel supply system in pulverized coal boiler OP-650}

The OP-650 boiler is a pulverized fuel front wall fired boiler with steam drum, natural water circulation and steam reheaters. General scheme of arrangement of the existing firing system in on exemplary boiler OP-650 is presented in Fig. 1. The installed firing system comprises twelve main burners in two burner levels and twelve low dust burners in one burner level above the OFA-1. The boiler has a start-up installation consisting of 12 heavy oil burners placed in pulverized fuel (PF) burners. The level of OFA-1 nozzles is permanently closed. The first two levels of burners are supplied with a high concentration mixture. The diluted coal-air mixture is provided to the third level of burners. All burners are enclosed in a common secondary wind-box, which is located on the front wall of the boiler. In addition to this, two more overfired air nozzles levels are also installed in boiler - OFA-2 (above the low-dust burners) and OFA-3 (on the rear wall).

The arrangement of individual burners and OFA nozzles in the boiler is presented in Fig. 2. The boiler is fed by six ring-ball mill units MKM-33 (marked alphanumeric A-F) and each mill feeds two main burners (swirltype) and two low-dust burners (without swirl). In Fig. 2 the distribution from each mill to the burners is described. The two lower levels of circles show the main burners. The small red circles inside the burners are the start-up oil burners. The color and description of each burner is assigned to 


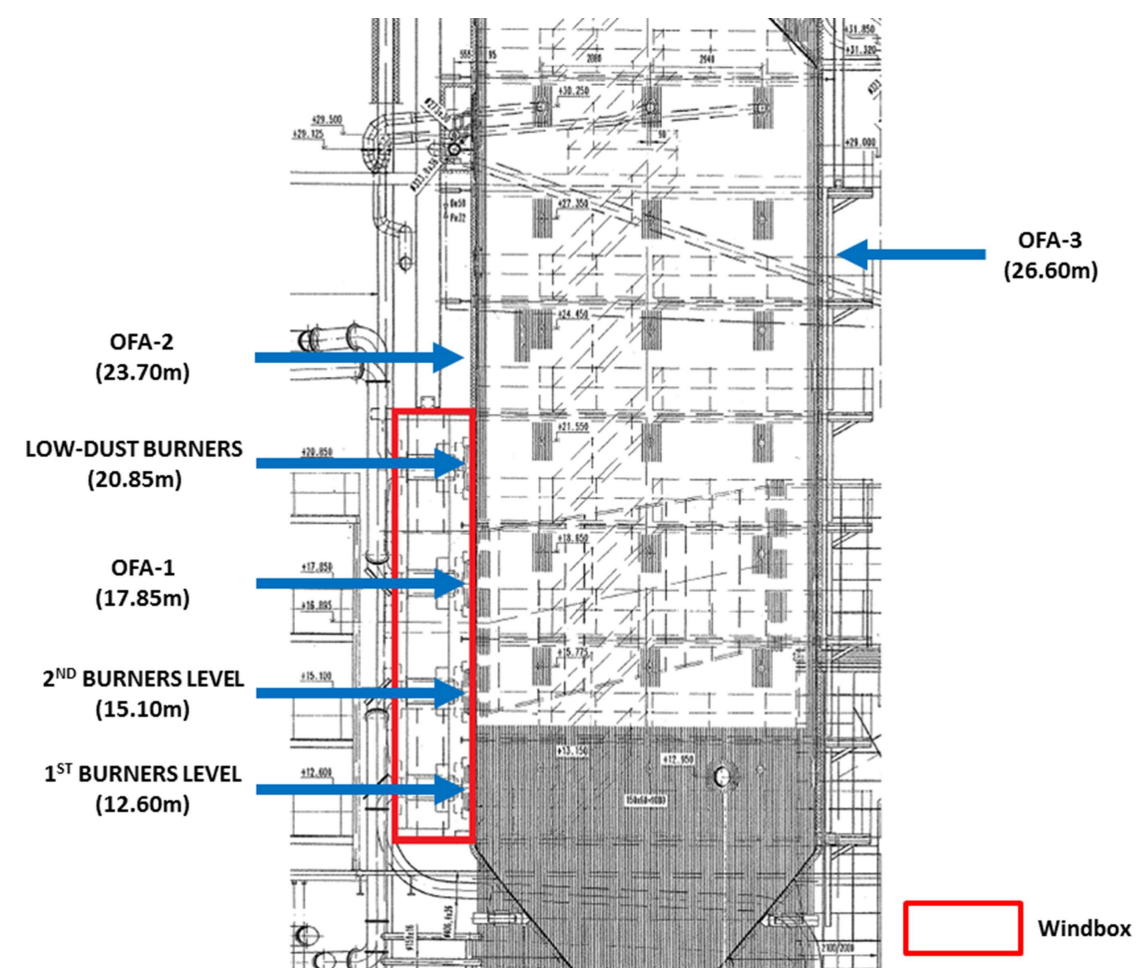

Figure 1: Arrangement of the exisiting firing system.

the proper mill, e.g., 'A1' means, the high-dust burner is supplied by mill 'A'. The combustion air of the main burners is separated into core, primary, secondary and tertiary. Above the main burners the first over fire air level is represented by blue rectangles (from 1R1 to 6R6). The OFA-1 level is out of operation. Next to the OFA-1 row the low-dust burners are located and are clustered in pairs. The burners injects the primary air with a low concentration of pulverized fuel into the furnace with certain amount of the secondary air to improve the ignition. Boiler consists of two additional level of OFA nozzles. The OFA-2 level is located above the windbox at the front wall and the nozzles operate in pairs (2R1-2R2, 2R3-2R4, 2R5-2R6). At the boiler's rear wall is OFA-3 level and the nozzles are controlled in two sections: 3R1-3R5 and 3R6-3R10. The described system of air and fuel staging in PC boiler OP-650 is an example of low-emission combustion system, which was designed to reach low-NOx conditions using primary methods. 


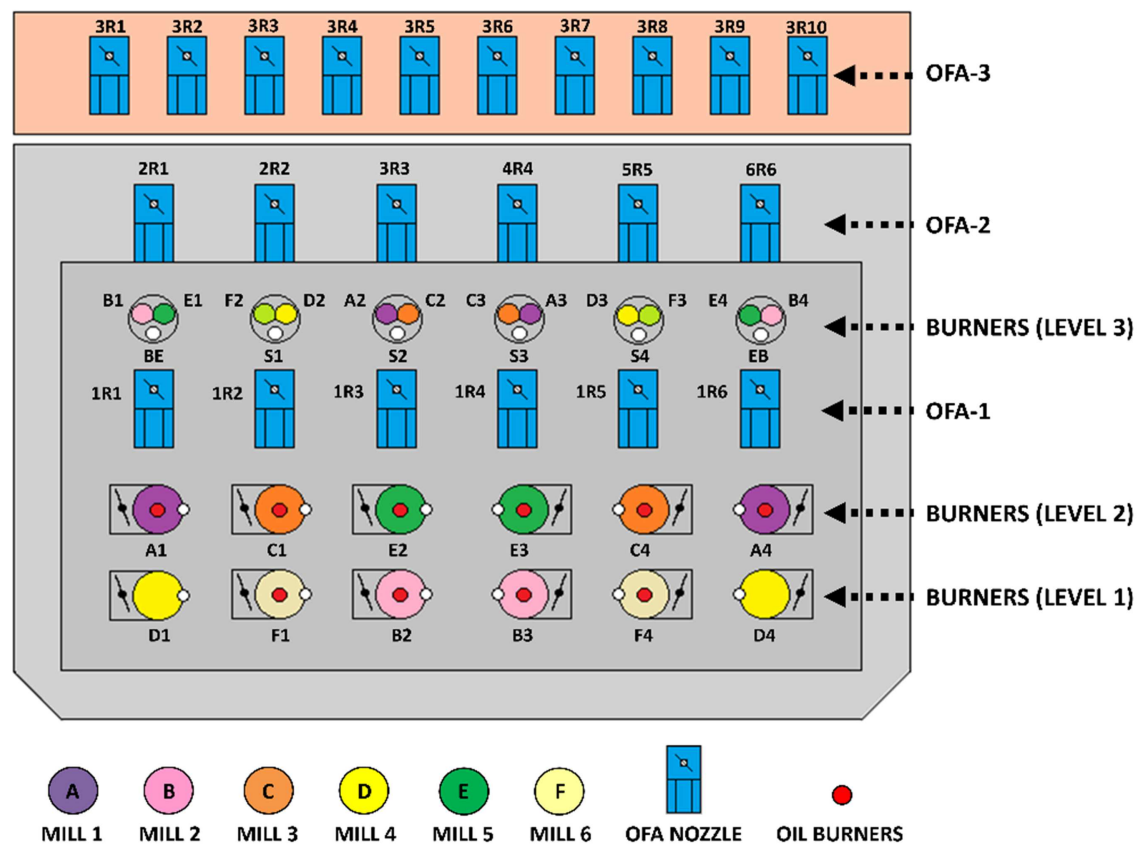

Figure 2: Arrangement of the exisiting firing system.

\subsection{Combustion air distribution system}

The OP-650 boiler is equipped with a three air-flue gas lines, designed to run and regulate the combustion process. Each line includes:

- RAPH - rotary air preheater (regenerative heat exchanger),

- ID fan - induced draft, exhaust fan (radial, with guiding vane on the suction side),

- FD fan - force draft, air fan (axial, variable speed rotor).

In addition, air-flue gas system contains:

- air and flue gas ducts with dampers,

- air intakes and silencers installed on the suction side of the FD fans.

The general scheme of combustion air and flue gas system is presented in Fig. 3. Three FD fans (FG1-3) supply the combustion air. Dampers in the main ducts to the windbox regulate the air volume flow to the main 
burners and OFA nozzles. Three regenerative air preheaters (RAPH1-3) preheat the hot air to the boiler. The two outer RAPHs (RAPH-1 and RAPH-2) are used to heat the secondary air to a temperature of approx. $275^{\circ} \mathrm{C}$. The air preheater in the center (RAPH-2) is used to heat the hot portion of the primary air (mill air) to a temperature of approx. $315^{\circ} \mathrm{C}$. The cold portion of the primary air is bypassed around the RAPH-2 and is mixed with the hot air directly before injecting into each mills. The secondary air to OFA-2 is taken form the windbox, whereas the secondary air to OFA-3 is derived from the main air-ducts behind the RAPH-1 and RAPH-2.

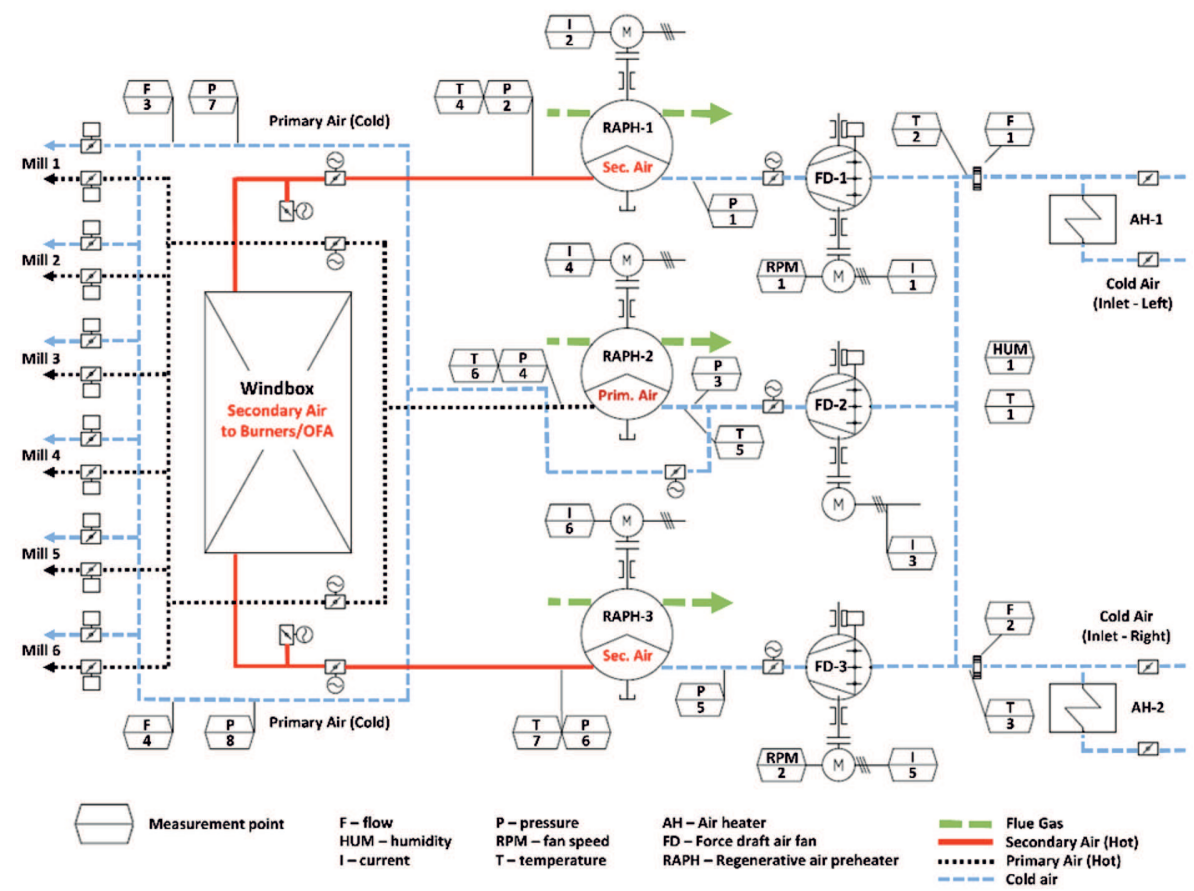

Figure 3: Arrangement of the piping and instrumentation diagram (PID) combustion air system.

\section{Model of air distribution in the OP-650 boiler}

Development and application of the air distribution modeling in coal-fired boiler is a complex process. Combustion air balance and the secondary air 
flow propagation can be analyzed using mathematical simulation software. Modern numerical tools provide solution algorithms with a wide range of component libraries for modeling and simulation of different types of thermal and hydraulic systems [15].

The simulation model of air distribution in the OP-650 boiler system proposed in this paper has been developed in EBSILON® Professional software. The general structure of combustion air system is presented in Fig. 4. The models have been designed based on existing technical documentation and available technological diagrams. The complete model of air-fuel-flue gas system was divided into two sub-models:

- main air-flue gas distribution model (Fig.4),

- air distribution to OFA-2 and OFA-3 (Fig.5).

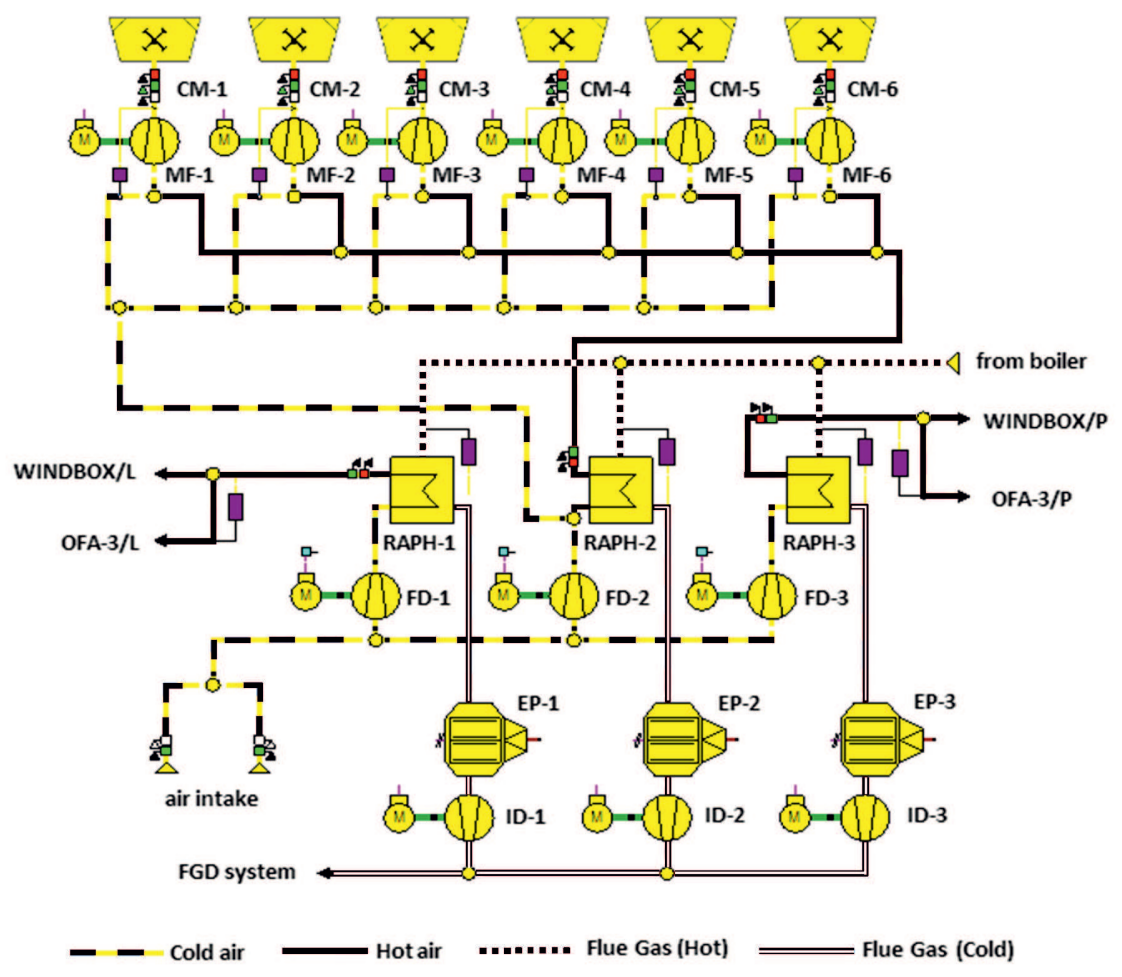

Figure 4: Model of air-flue gas distribution system. 
The mathematical model of air flow in a boiler piping/duct system takes into account the variation of air temperature and pressure due to friction, as well as heat losses. The air pipe is designed phenomenologically, which means that the amount of heat losses and the extent of the pressure drop are entered in the design case. The nominal values of pressure and heat losses of air ducts were assumed in design case based on the operating data and technical specification of the OP-650 boiler. In off-design calculations the losses are scaled accordingly. However, in EBSILON® Professional software is also possible to calculate the pressure drop based on the pipe geometry (length, inner diameter, wall roughness). The phenomenological pressure drop method was used in the simulation model of air distribution.

In the off-design calculations the pressure drop results according to Bernoulli's principle with consideration of mass flow and the specific volume [15]:

$$
\triangle p_{1-2}=\triangle p_{1-2 N}\left(\frac{\dot{V}_{1}}{\dot{V}_{1 N}}\right)\left(\frac{\dot{m}_{1}}{\dot{m}_{1 N}}\right)^{2},
$$

where: $\triangle p_{1-2}-$ pressure drop between pipe inlet and outlet (off-design mode), $\triangle p_{1-2 N}$ - nominal pressure drop between pipe inlet and outlet, $\dot{V}_{1}$ - specific volume at pipe inlet (off-design mode), $\dot{V}_{1 N}$ - nominal volume at pipe inlet, $\dot{m}_{1}$ - mass flow at pipe inlet (off-design mode), $\dot{m}_{1 N}$ - nominal mass flow at pipe inlet.

The heat losses are specified in the design case, but in off-design calculations the temperature loss is scaled quadratically with the flow [15]

$$
\triangle t_{1-2}=\triangle t_{1-2 N}\left(\frac{\dot{m}_{1}}{\dot{m}_{1 N}}\right)^{2},
$$

where: $\triangle t_{1-2}-$ temperature drop between pipe inlet and outlet (off-design mode), $\triangle t_{1-2 N}-$ nominal temperature drop between pipe inlet and outlet.

In order to determine the air flow to each OFA nozzles the control valve components (with flow coefficient) were used in off-desing simulation. This component describes the relationship between the pressure difference and the corresponding flow rate through a control valve. In desing simulation the flow coefficient $K_{v}$ is calculated according to the following formula [15]:

$$
K_{v}=\frac{\dot{V}_{1}}{Y} \sqrt{\frac{\triangle p_{0}}{\triangle p} \frac{\rho}{\rho_{0}}}
$$

where: $\dot{V}_{1}$ - volumetric flow rate at valve inlet, $Y$ - expansion factor, $\triangle p_{0}$ - reference pressure drop (for SI definition 0.1 MPa), $\rho_{0}$ - reference density 
(for SI definition - $1000 \mathrm{~kg} / \mathrm{m}^{3}$ ).

Whereas in the off-design simulation the volumetric flow rate at nozzle inlet is computed depending on the nozzle position and pressure difference. The $K_{v}$ factor is a relative measure of nozzle efficiency at allowing fluid flow.

The sum of secondary air flow to burners is calculated as the difference between the total air flow to three regenerative air preheaters (RAPH1-3) and sum of air flow to OFA-2 and OFA-3 nozzles. It has been assumed that the air flow to each burners is calculated in proportion to the damper position of the burners.

The structure of the simulation model presented in Fig. 4 contains following components: air fans with motors (FD), regenerative heat exchangers (RAPH), electrostatic precipitators (EP), exhaust fans with motors (ID), six coal mills (CM) with fans (MF), flue-gas desulfurization system (FGD). The description of the air and flue gas distribution was presented in Sec. 2.

\subsection{Secondary air flow to OFA model}

The simulation model of the secondary air flow in air ducts to the OFA-2 and OFA-3 nozzles was developed using the data contained in the available technical documentations for OP-650 boiler. The geometry of the exhaust and air duct system was included in the model based on technological schemes. The structure of the secondary air distribution model to OFA-2 and OFA-3 is presented in Fig. 5.

Simulation model of air flow to OFA nozzles takes into account following elements:

- air inlets to the nozzles OFA-2, which are controlled in pairs: OFA-2/1 - OFA-2/2 (left side), OFA-2/3-OFA-2/4 (middle), OFA-2/5-OFA$2 / 6$ (right side), and outlet to the combustion chamber at the level of $23.7 \mathrm{~m}$;

- air inlets to nozzles OFA-3, which are controlled by the five per side: OFA-3/1-5 (left side), OFA-3/6-10 (right side) and an outlet to the combustion chamber at the level of $26.6 \mathrm{~m}$;

- logical lines, which allow setting value of a required opening degree of the OFA damper.

The identification process of available measuring points in the area of the windbox and burner chamber of the analyzed boiler, showed that in the 


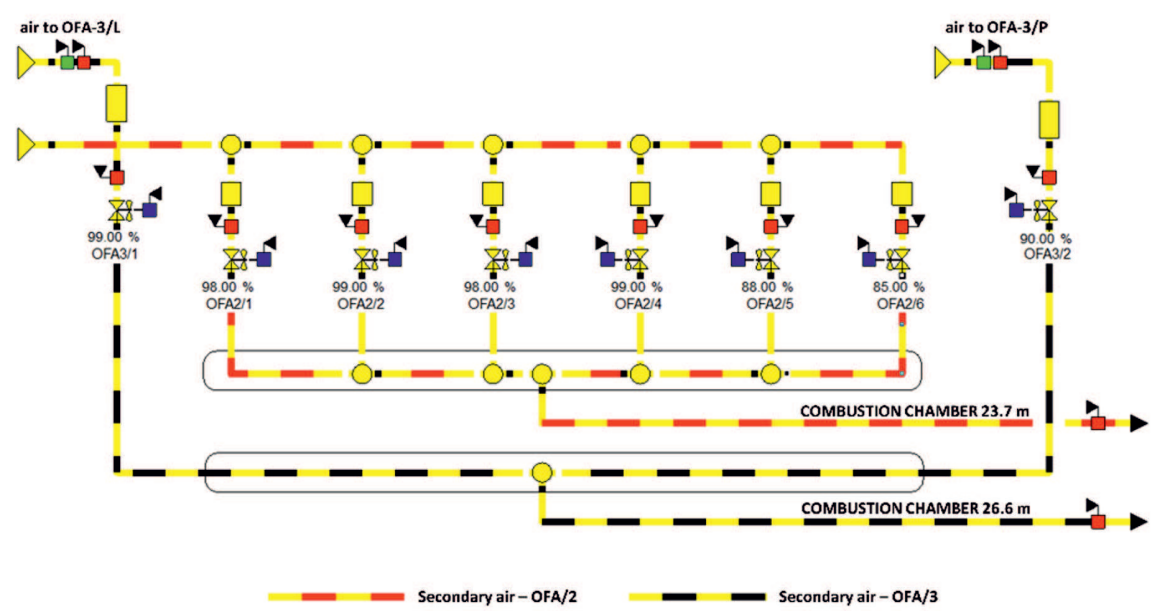

Figure 5: Model of air distribution system to OFA-2 and OFA-3.

measuring system there was no information about the pressure values in the OFA-2 and OFA-3 air ducts. The assembly of eight additional pressure measurements was proposed and installed:

- six pressure measurements in OFA-2 ducts,

- two pressure measurements in OFA-3 ducts (left and right side).

The secondary air flow to OFA nozzles can be simulated by changing: temperature and air pressure in the duct to the OFA nozzles, pressure in the windbox and combustion chamber (at level $23.6 \mathrm{~m}$ and $26.6 \mathrm{~m}$ ) and the damper opening degree of the selected OFA nozzle. The main results, which can be obtained from the simulation model of secondary air distribution are the air flows to the OFA-2 and OFA-3 nozzles. These values were not measured in the boiler system.

\section{Verification test of simulation models}

One month measurement campaign, in order to determine the balance and air distribution in the boiler OP-650 at the real power plant was carried out. The developed simulation mathematical models of air distribution in OP650 boiler was subjected to a verification process. The simulation results were compared with the values obtained from the reference measurements 
and modeling based on 'virtual' airflow sensors (VS), which allow determining the total primary, secondary and OFA nozzles based on available DCS measurements. VS technology is based on the development of the physical model of the hydraulic network of the selected facility, including piping, manifolds, control valves and fans. So far, the system has been implemented in coal-fired power plants from 100 MWe to 1000 MWe, where it has successfully contributed to identifying and improving the distribution of air in coal boilers [16]. Based on the measurements and calculations from VS the air balance for the OP-650 boiler was determined. The data registered during the tests were analyzed in order to calculate the air flow balance of the OP-650 boiler and to compare the experimental values with the results from the simulation mathematical model.

One of the unknown of the developed model was how to determine the secondary air flow through the burners. For the purposes of the simulations, it was assumed that the amount of secondary air reaching the burners from the windbox together with the primary air should provide an excess air ratio of 0.7 , at burners belt (in design mode) $[5,7,8]$. Additionally, it was also assumed that the pressure in the combustion chamber at level $23.7 \mathrm{~m}$ and $26.6 \mathrm{~m}$ is the arithmetic mean of the measured values available at this level. The complete list of input data needed to perform the simulation calculations is presented in Tab. 1. All listed parameters used in the calculation as input data are available in the DCS system.

\subsection{Verification results}

To verify the developed simulation model of air distribution in OP-650 boiler, comparisons between the simulated values and VS measurement data of a boiler operated under steady state and transient conditions were made. The verification process was carried out for a full day of boiler operation. In order to determine the correctness of the developed model, the results of the simulation calculations were compared with the results of the reference VS model and with the measurement values from the DCS system. Based on the results of the simulation calculations and measurements, the following parameters were compared:

- total air flow to boiler,

- primary air flow,

- secondary air flow to burners and secondary air flow to OFA-2 and OFA-3. 
Table 1: Input parameters for simulations.

\begin{tabular}{|l|l|c|}
\hline No. & Measuring point description & Unit \\
\hline \hline 1 & Air flow to RAPH-1-3 & $\mathrm{kNm}^{3} / \mathrm{h}$ \\
\hline 2 & Total primary air flow to mill CM-1-6 & $\mathrm{kNm}^{3} / \mathrm{h}$ \\
\hline 3 & $\begin{array}{l}\text { Damper position burner A1, A4, B2, B3, C1, } \\
\text { C4 }\end{array}$ & $\%$ \\
\hline 4 & $\begin{array}{l}\text { Damper position burner D1, D4, E2, E3, F1, } \\
\text { F4 }\end{array}$ & $\%$ \\
\hline 5 & Nozzle position OFA II - 1-6 & $\%$ \\
\hline 6 & Nozzle position OFA III - left and right side & $\%$ \\
\hline 7 & $\begin{array}{l}\text { Pressure in comb. chamber (level 23.7 m) }- \\
\text { left, right and middle side }\end{array}$ & $\mathrm{Pa}$ \\
\hline 8 & $\begin{array}{l}\text { Pressure in comb. chamber (level 17.5 m) } \\
\text { left and right side }\end{array}$ & $\mathrm{Pa}$ \\
\hline 9 & $\begin{array}{l}\text { Pressure in comb. chamber (level 10.5 m) }- \\
\text { left and right side }\end{array}$ & $\mathrm{Pa}$ \\
\hline 10 & Pressure in windbox - left and right side & $\mathrm{Pa}$ \\
\hline 11 & Air pressure in OFA-2/1-6 & $\mathrm{Pa}$ \\
\hline 12 & Air pressure in OFA-3 left and right side & $\mathrm{Pa}$ \\
\hline 13 & Air pressure behind RAPH-1 & $\mathrm{Pa}$ \\
\hline 14 & Air temperature behind RAPH-1 & ${ }^{\circ} \mathrm{C}$ \\
\hline 15 & Air pressure behind RAPH-3 & $\mathrm{Pa}$ \\
\hline 16 & Air temperature behind RAPH-3 & - \\
\hline 17 & Excess air ratio & ${ }^{\circ}$ \\
\hline
\end{tabular}

The verification results of total air flow into the boiler is presented in Figs. 6 and 7 . The results showed that the developed simulation model can describe the physical behavior of air distribution in OP-650 boiler with small differences from the reference values Eq. (3). In order to determine the difference between the results obtained from the simulation model and from VS modeling, the relative error was calculated according to the following formula:

$$
\triangle x_{i}=\left(\frac{x_{i} R E F-x_{i} E B S}{x_{i} R E F}\right) \times 100 \%
$$

where: $x_{i E B S}$ - value of $i$ th parameter from simulation calculation (Ebsilon), $x_{i} R E F-$ value of $i$ th parameter from reference measurment (EUtech). 
The obtained values of relative errors are presented in Tab. 2 .
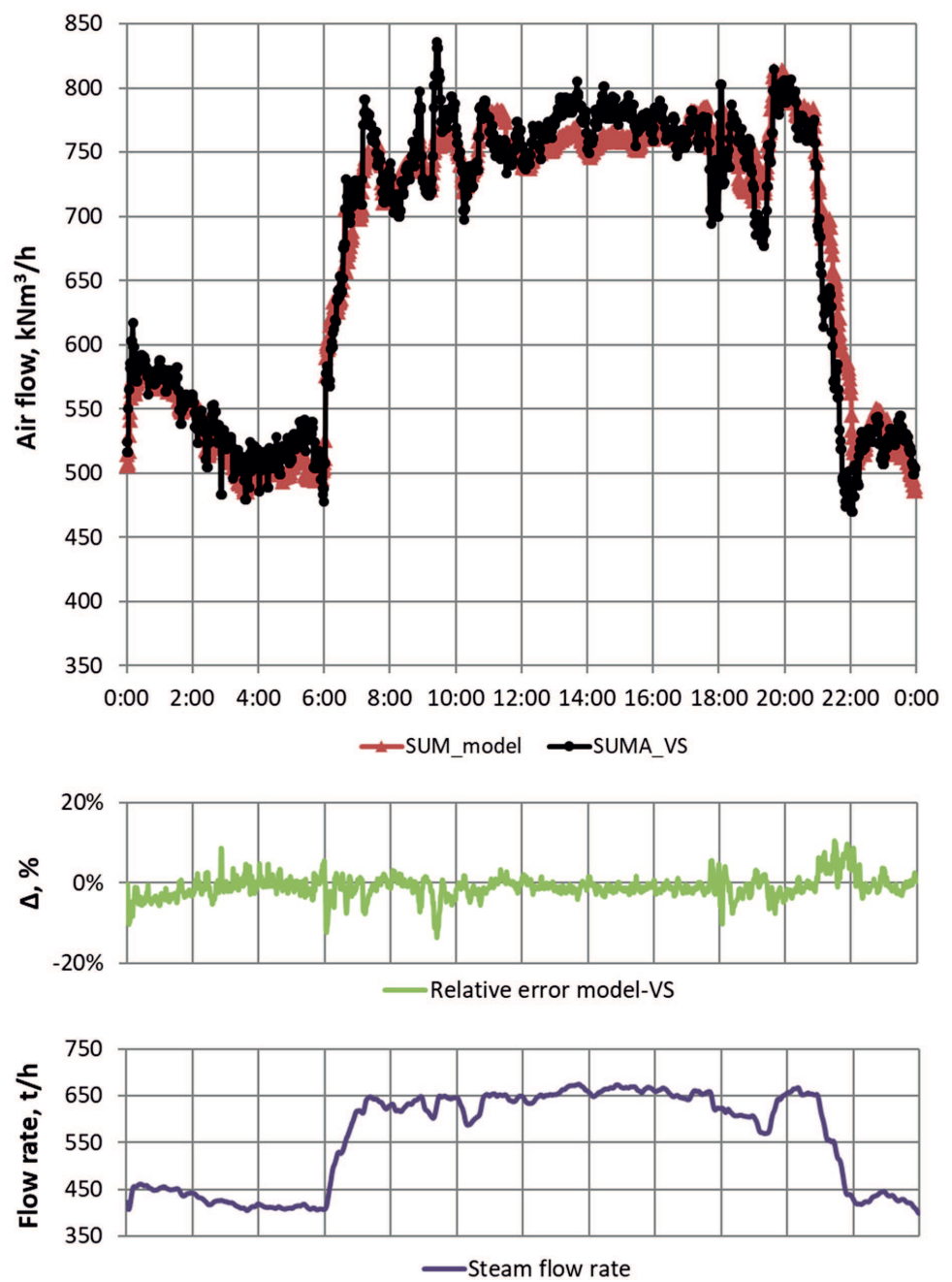

Figure 6: Verification results of total air flow into the boiler.

The average value of relative error obtained from the verification results did not exceed $6.0 \%$. Based on the verification process, it can be confirmed that the developed simulation model of air distribution ensures high results accuracy in the whole range of boiler operation - steam flow rate in range $390-680 \mathrm{t} / \mathrm{h}$. 

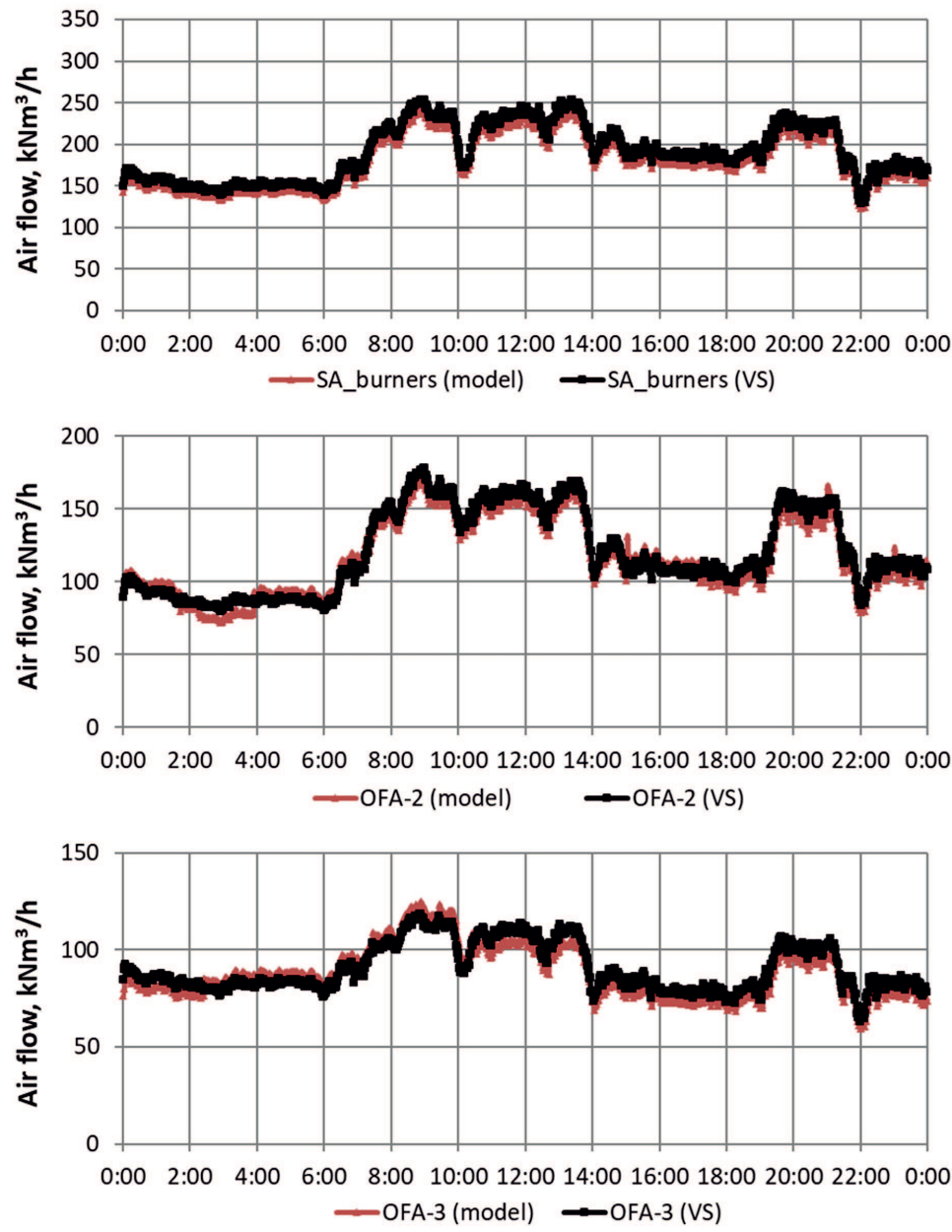

Figure 7: Verification results of secondary air (SA) flow into burners, OFA-2 and OFA-3.

The developed simulation mathematical model of air distribution has been tested and implemented in the OP-650 boiler operation system at the EDF Polska S.A. power plant in Rybnik. The values of secondary air flow to each burners and OFA nozzles have been introduced in the operating system of the analyzed boiler. Visualization graphic of existing firing system in OP-650 boiler with new air flow measurement points is presented in Fig. 8 (dashed frame). 
Table 2: Relative error results

\begin{tabular}{|l|c|c|c|c|}
\hline Parameter | Steam flow rate & $600-680 \mathrm{t} / \mathrm{h}$ & $480-600 \mathrm{t} / \mathrm{h}$ & $390-480 \mathrm{t} / \mathrm{h}$ & Average \\
\hline \hline Total air flow & $1.8 \%$ & $2.9 \%$ & $2.4 \%$ & $2.1 \%$ \\
\hline Secondary air flow to burners & $4.3 \%$ & $2.6 \%$ & $2.1 \%$ & $3.4 \%$ \\
\hline Secondary air flow to OFA-2 & $4.2 \%$ & $6.0 \%$ & $4.5 \%$ & $4.7 \%$ \\
\hline Secondary air flow to OFA-3 & $5.5 \%$ & $7.3 \%$ & $5.7 \%$ & $6.0 \%$ \\
\hline
\end{tabular}

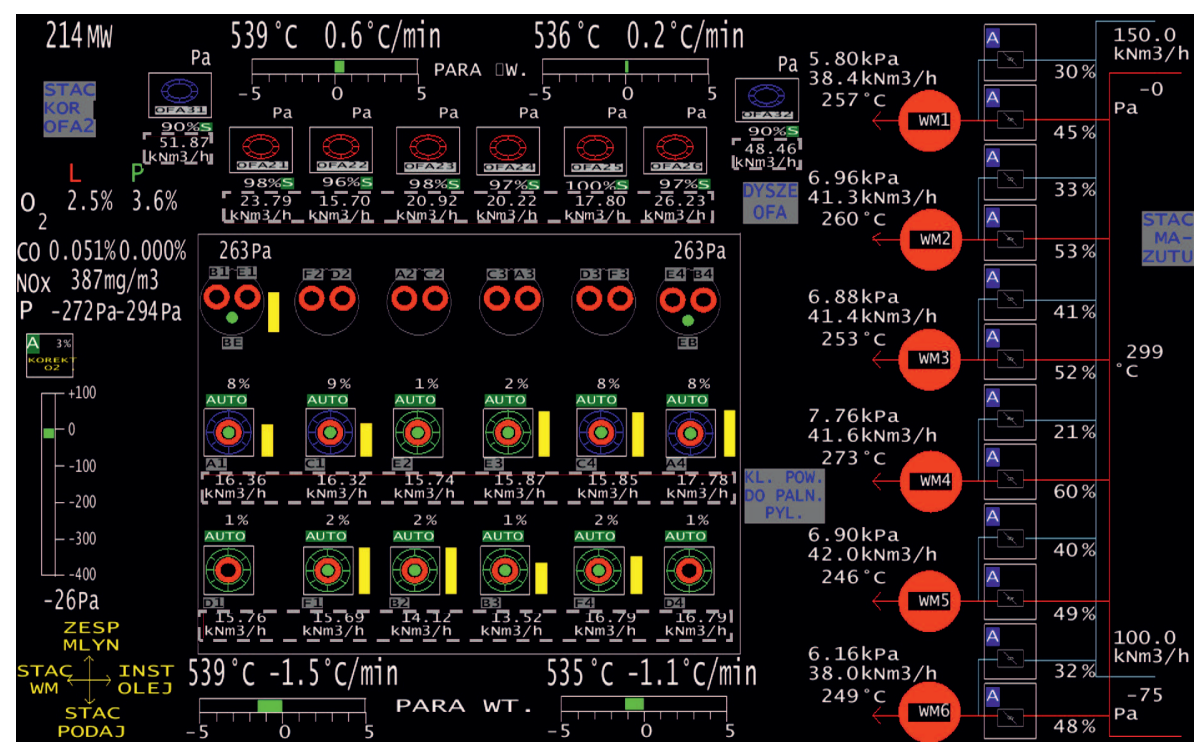

Figure 8: Firing system visualization graphic with new air flow measurement points.

\section{Conclusions}

Although the technology of pulverized coal-fired boiler is well known, there is still room for further improvement concerning optimization of the combustion process and proper control of combustion air distribution, which can be done using mathematical modeling. In this paper, the novel online monitoring system of air distribution in coal-fired boiler based on realtime numerical calculations has been presented. The developed simulation model allows for identification of mass flow rates of secondary air to individual burners and to OFA nozzles. The calculated results obtained from the 
simulation were compared with the values from the reference measurements and VS modeling. The following parameters were used in the verification procedure: total air mass flow rate to the boiler, secondary air mass flow rate to the burners, secondary air mass flow rate to OFA-2 and to OFA-3 nozzles. Based on the results obtained from verification of the air distribution mathematical model, it can be concluded that the compatibility of results from the simulations and from the reference measurement campaign is very satisfactory. The average relative error value did not exceed $6.0 \%$.

The presented numerical model for real-time monitoring of air distribution is capable of giving continuous determination of the total air flows (PA, SA and OFA) from available DCS data. The developed mathematical model has been successfully implemented in the real DCS control system. In the next stages of this research, there is a plan to analyze possibility to combine the developed air flow model with an advanced optimization software, to get optimal control of burners and OFA dampers [9].

Received 30 September 2017

\section{References}

[1] Modliński N., Madejski P., Janda T., Szczepanek K., Kordylewski W.: A validation of computional fluid dynamics temperature distirbution prediction in a pulverized coal boiler with acoustic temperature measurement. Energy 92(2015), $77-86$.

[2] Madejski P., Janda T., Modliński N., Nabageo D.: A combustion process optimization and numerical analysis for the low emission operation of pulverized coal-fired boiler. Chap. in Developments in Combustion Technology. InTechOpen, 2016, 33-76.

[3] Taler J., Trojan M., Taler D., Dzierwa P., Kaczmarski K.: Improving flexibility characteristics of $200 \mathrm{MW}$ unit. Arch. Thermodyn. 38(2017), 1, 75-90.

[4] Szargut J., ZięBIK A.: Fundamentals of Heat Engineering. PWN, Warszawa 1998.

[5] Chmielniak T.: Energy Technologies. WNT, Warszawa 2015.

[6] Pronobis M.: Modernisation of Power Boilers. WNT, Warszawa 2013.

[7] Taler D., Madejski P.: Thermomechanical CSM analysis of a superheater tube in transient state. Arch. Thermodyn. 32(2011), 3, 117-126.

[8] NabagŁo D., MadeJSKi P.: Combustion process analysis in boiler OP-650k based on acoustic gas temperature measuring system. In: Proc. 3rd Int. Conference on Contemporary Problems of Thermal Engineering, 2012.

[9] Śladewski Ł., Wojdan K., Świrski K., Janda T., NabagŁo D., ChachuŁa J.: Optimization of combustion process in coal-fired power plant with utilization of acous- 
tic system for in-furnace temperature measurement. Appl. Therm. Eng. 123(2017), $717-720$.

[10] HeRniK B: Numerical modeling of BP 1150 boiler by commercial numerical code. J. Power Technologies 92(2012), 34-47.

[11] Chen H., Liang Z.: Damper opening optimization and performance of a co-firing boiler in a 300 MWe plant. Appl. Therm. Eng. 123(2017), 865-873.

[12] Purimetla A., Cui J.: CFD studies on burner secondary airflow. Appl. Math. Model. 33(2009), 1126-1140.

[13] Gou X., Zhang Z.: Real-time Model and Simulation of Combustion System in a 440t/h CFB Boiler. In: Challenges of Power Engineering and Environment - Proc. Int. Conf. on Power Engineering 2007, 226-230.

[14] Vijiapurapu S., Cui J., Munukutlab S.: CFD application for coal/air balancing in power plants. Appl. Math. Model. 30(2006), 854-866.

[15] Steag Energy Services GmbH. Ebsilon Professional software, version 12.02.01. Wetzbach Germany (2016).

[16] Scientific EUtech Engineering GmbH. https://www.eutech-scientific.de 